\title{
A REDE MERCOCIDADES NA INTEGRAÇÃO SUL-AMERICANA: A PARADIPLOMACIA NO MERCOSUL E NA UNASUL
}

Joséli Fiorin Fiorin Gomes ${ }^{1}$

\section{Resumo}

Verificam-se no cenário contemporâneo das relações internacionais duas realidades irreversíveis: a integração regional e a paradiplomacia. Estes dois fenômenos encontram um ponto de conexão na atuação da Rede Mercocidades, formada, inicialmente, para viabilizar a participação dos governos locais no processo de integração do MERCOSUL. Mas, com o incremento da relevância das cidades no plano internacional, visualiza-se a possibilidade de a Rede contribuir para inseri-las também no processo mais amplo da UNASUL. Nesse passo, o estudo visa a examinar duas questões. A primeira aborda a atuação da Rede Mercocidades junto ao MERCOSUL. A partir disso, a segunda questão refere-se a averiguar a possibilidade de expansão da atuação da Rede em direção à UNASUL, bloco com o qual o MERCOSUL estabelece relações de complementaridade.

Palavras-chave: Integração; Paradiplomacia; Mercocidades; MERCOSUL; UNASUL.

\begin{abstract}
The contemporary setting of international relations presentes two irreversible realities: regional integration and paradiplomacy. These two phenomena find a connection point in the performance of the Mercociudades Network, which was initially formed to enable the participation of local governments in MERCOSUR's integration process. However, with the increased international importance of cities, a possibility for this Network to help bring them into the broader process of UNASUR is foreseen. In this sense, the study aims to examine two questions. The first discusses the role of Mercociudades Network within MERCOSUR. Thus, the second question refers to investigate the possility of expanding its connections towards UNASUR, a bloc with which MERCOSUR established complementary relations.
\end{abstract}

Key Words: Integration; Paradiplomacy; Mercociudades; MERCOSUR; UNASUR.

${ }^{1}$ Doutoranda em Direito pela UFRGS. Mestre em Direito Público pela UNISINOS. Especialista em Direito Internacional pela UFRGS. Professora do Curso de Relações Internacionais do UNIRITTER. 
53 | InterAção

\section{INTRODUÇÃO}

No cenário atual das relações internacionais, a integração regional é realidade inegável e, possivelmente, irreversível, constituindo-se em parte essencial das agendas de política externa de diferentes países. Este contexto é particularmente evidente na América do Sul, em que, pelas proximidades territorial e cultural, bem como por convergências políticas e econômicas, há certa interdependência entre os países da região. Com isso, este artigo aborda a interação entre iniciativas de integração regional que têm demonstrado persistência e resultados na América do Sul: a Rede Mercocidades, o Mercado Comum do Sul (MERCOSUL) e a União das Nações Sul-Americanas (UNASUL).

Tanto a Rede Mercocidades, como o MERCOSUL e UNASUL, são organismos que objetivam e priorizam a integração da América do Sul, fornecendo espaço para promoção da cooperação e o desenvolvimento da região. Mas, nestes dois últimos organismos, inicialmente, os processos deliberativos e decisórios eram centrados apenas nos governos nacionais. A Rede Mercocidades, frente a isso, foi formada para buscar a participação dos governos locais na integração mercosulina. A importância da participação de governos subnacionais na integração regional se dá pelo fato destes governos estarem mais próximos aos problemas e demandas dos cidadãos do que os governos nacionais. Nesse sentido, a Rede Mercocidades visa a que os atores subnacionais tornam-se protagonistas, adquirindo voz e espaço de atuação para melhoria das políticas sul-americanas. Assim, além de incluí-los no âmbito do MERCOSUL, a Rede pode contribuir para inserir esses atores no processo mais amplo da UNASUL.

Nesse passo, este trabalho visa a examinar duas questões. A primeira destina-se a perquirir sobre a atuação da Rede Mercocidades junto ao MERCOSUL, tendo em vista que fora criada para favorecer a participação das 
54 | InterAção

cidades junto a este bloco regional. A partir disso, a segunda questão refere-se a averiguar quais as possibilidades de expansão da atuação da Rede em direção à UNASUL, bloco com o qual o MERCOSUL estabelece relações de complementaridade, em razão de a Rede visar ao aprofundamento do protagonismo das cidades na integração regional sul-americana. É o que se tratará a seguir.

\section{A REDE MERCOCIDADES E SUAS RELAÇÕES COM O MERCOSUL: EXEMPLO DA PARADIPLOMACIA NA INTEGRAÇÃO REGIONAL SUL-AMERICANA}

O panorama contemporâneo é marcado pela larga interação entre os âmbitos global, regional e local. O que ocorre num destes cenários logo se reflete nos demais. A recíproca influência entre estas diversas, mas complementares, cenas é, com isso, experimentada cotidianamente nas cidades. Nesse sentido, estas têm se tornado, cada dia mais, atores essenciais nas relações internacionais. A diplomacia, então, tem que se adaptar aos novos tempos, já que a ideia de que as relações internacionais apenas são realizadas pelo e para os governos nacionais centrais tornou-se obsoleta (TAVARES, 2013). Em função disso, surge o fenômeno da paradiplomacia². Segundo Fronzaglia, esta pode ser caracterizada como

(...) o conjunto de atividades desenvolvidas pelas unidades subnacionais - de maneira isolada ou conjunta - conforme seu grau de autonomia e que visam sua inserção internacional podendo ser complementares, paralelas ou conflitantes com a

\footnotetext{
2 Segundo Duchacek (1990, p.16-27), a paradiplomacia envolve apenas os assuntos de low politics, não se referindo a iniciativas dos governos federados sobre temas de segurança nacional. Nesse passo, 0 autor a identifica como microdiplomacia, em oposição à macrodiplomacia, que consistiria na diplomacia tradicional dos governos centrais a respeito das questões estratégicas do país (1990, p. 18). No mesmo sentido, Rodrigues (2004) refere-se ao fenômeno como "política externa federativa", sustentando que o enfoque recai sobre os interesses e necessidades locais.
} 
55 | InterAção

diplomacia conduzida pelo governo central. (FRONZAGLIA, 2005, p. 50)

Frente a isso, trata-se de processo de atuação de entes subnacionais ${ }^{3} \mathrm{em}$ que interesses e demandas regionais ou locais, de cunho político, econômico e cultural, são estabelecidos de modo global, trazendo-lhes maior legitimidade e a possibilidade de encontrar novos parceiros no âmbito internacional. Nesse viés, a inserção internacional das cidades tem papel relevante para a concretização da integração regional. Esta objetiva fortalecer os países, mediante cooperação econômica, política, social e cultural, ao promover o desenvolvimento e a melhoria da qualidade de vida das suas populações. Parece ser este o caso do MERCOSUL. Para que as decisões tomadas no bloco pudessem ser influenciadas pelos governos locais, criou-se, em 1995, a Rede Mercocidades.

A Rede Mercocidades é uma organização de cooperação descentralizada4, formada pelos governos locais da região sul-americana, sendo, atualmente, composta por 286 cidades da Argentina, Brasil, Paraguai, Uruguai, Venezuela, Chile, Bolívia, Colômbia e Peru. A Rede visa a proporcionar a inserção das cidades sócias no processo de integração regional do MERCOSUL, bem como em outros foros internacionais. Nesse sentido, objetiva fomentar o desenvolvimento de ações, programas e projetos de interesse intermunicipal, que se relacionem ao processo de integração. Permite, com isso, o intercâmbio de experiências e informações entre as cidades associadas, a fim de qualificar a prestação de

\footnotetext{
30 termo é utilizado pela literatura especializada de modo majoritário, buscando identificar os governos dos Estados e Municípios da federação brasileira, assim como outras figuras políticas congêneres, presentes na organização dos demais Países, diferenciando-as dos governos centrais destes. No entanto, há aqueles, como Castelo Branco (2007, p. 56) e Prazeres (2004, p. 283), que entendem que seria mais apropriado tecnicamente, para tratar do fenômeno da paradiplomacia e dos entes não centrais, utilizar o termo "subestatais" em vez de "subnacionais", para respeitar a distinção entre Estado e Nação.

${ }^{4}$ Cooperação horizontal ou descentralizada trata-se da relação substancial colaborativa entre governos subnacionais de diferentes países, com vistas ao desenvolvimento local sustentável, o que implica em algumas formas de trocas e suportes conduzidas por estas instituições ou outros atores locais entre si. (HAFTEK, 2003, p. 336; ANDRADE E BARROS, 2010, p. 6-10).
} 
56 | InterAção

serviços e a infra-estrutura urbana, em prol do desenvolvimento e melhoria das condições de vida nas cidades (MERCOCIUDADES, 2014a). Portanto, trata-se de exemplo do fenômeno da paradiplomacia na integração regional sul-americana.

Diante disso, a Rede é organizada numa estrutura que conta com diversos órgãos ${ }^{5}$. Dentre estes, deve-se destacar suas 15 (quinze) Unidades Temáticas (UTs). As Unidades Temáticas dedicam-se aos seguintes temas: Ambiente e Desenvolvimento Sustentável; Autonomia, Gestão e Financiamento Municipal; Ciência, Tecnologia e Capacitação; Cooperação internacional; Cultura; Esportes; Desenvolvimento Econômico Local; Desenvolvimento Social; Desenvolvimento Urbano; Educação; Gênero e Município; Juventude; Planificação Estratégica; Segurança Cidadã; Turismo e Integração Fronteiriça (MERCOCIDADES, 2014d). No âmbito de algumas destas UTs, há, ainda, 6 (seis) grupos e comissões de trabalho. Os grupos de trabalho são os de Cooperação Descentralizada (junto à UT de Cooperação Internacional), Esportes (junto à UT de Cultura), e de Incapacidades e Inclusão (junto à UT de Desenvolvimento Social), enquanto as Comissões são de Economia Social e Solidária e de Fomento de Negócios (junto à UT de Desenvolvimento Econômico Local) e de Direitos Humanos (junto à UT de Desenvolvimento Social). (MERCOCIUDADES, 2014c).

Estas UTs, bem como seus respectivos GTs e Comissões, discutem temas e realizam ações de interesse local e repercussão internacional. Permitem a troca

\footnotetext{
50 principal destes é a Assembleia Geral, para deliberação e direção da Rede, constituída pelos chefes de governo das cidades, a qual se reúne anualmente. Para auxiliá-la há o Conselho, integrado por oito cidades dos países membros do MERCOSUL e quatro cidades dos países associados (MERCOCIUDADES, 2014b). Para representar a Rede, há a Secretaria Executiva, que colabora com os demais órgãos, convocando e presidindo as suas reuniões. Em cada período, a cidade que a exerce segue um plano de trabalho aprovado na Cúpula anual da Rede e seu mandato é de um ano, a partir da reunião da Assembleia Geral. Até dezembro de 2014, é exercida pela cidade de Porto Alegre. Como órgãos auxiliares da Secretaria Executiva, há a Comissão Diretiva e a Secretaria Técnica Permanente. Aquela presta apoio nas atividades de coordenação da Rede e é composta por três cidades, a que exerce a Secretaria Executiva, a que a exerceu no período imediatamente anterior e a que será a próxima a exercê-la. Já a Secretaria Técnica, com sede em Montevidéu, Uruguai, objetiva desenvolver a memória institucional da Rede, apoiar e assessorar o trabalho técnico e administrativo da Secretaria Executiva, acompanhar temas e debates sobre o processo de integração mercosulino e manter o contato com a Secretaria do MERCOSUL. (MERCOCIUDADES, 2014a).
} 
$57 \mid$ InterAção

de experiências entre as cidades, para ampliar o seu desenvolvimento econômico e social. Contam com a Coordenação de uma das cidades sócias e a subcoordenação de outras destas, realizando reuniões periódicas ao ano, para tratar das atividades pertinentes à suas temáticas que se desenvolvem em cada município participante. (MERCOCIUDADES, 2014a).

Ao contar órgãos especializados para expressar os interesses e demandas municipais, a Rede necessitava ter representação mediante uma estrutura jurídico-administrativa no MERCOSUL. Para tanto, estabeleceu-se o Foro Consultivo de Municípios, Estados Federados, Províncias e Departamentos do MERCOSUL (FCCR) ${ }^{6}$. Este órgão consultivo foi criado pela Decisão n. 41/2004 do CMC, estando atrelado ao GMC, órgão executivo do MERCOSUL. Sua finalidade é estimular o diálogo e a cooperação entre as autoridades locais, tendo competência para propor medidas de coordenação de políticas para promoção do bem-estar e melhoraria da qualidade de vida dos habitantes da região, bem como formular recomendações ao GMC. (MERCOSUL, 2004).

Este órgão é formado pelo Comitê de Municípios (COMUM) e pelo Comitê de Estados Federados, Províncias e Departamentos (CEFPD), bem como por uma Coordenação Geral, composta por Coordenadores Nacionais dos países do bloco (MERCOSUL, 2004). Conta, ainda, com uma Secretaria Técnica Permanente, também de representantes nacionais (FCCR, 2014). O COMUM, por disposição

\footnotetext{
${ }^{6}$ Inicialmente, criou-se a Reunião Especializada de Municípios e Intendências (REMI), um órgão auxiliar do Grupo Mercado Comum (GMC), em 2000. No entanto, esta encontrou diversas barreiras. Segundo Kleinman (2010, p. 61),"criada mais com a finalidade de tratar os governos locais como "tema", ao invés de envolvê-los no processo amplo de integração como atores e parceiros estratégicos, logo se mostrou um órgão burocrático e pouco propício à construção de uma agenda comum entre governos locais e nacionais. Coordenada por burocratas vinculados às chancelarias e pouco familiarizados com a agenda local, a REMI em pouco tempo tornou-se um espaço de desgaste, desânimo e, não raro, conflito entre instancias e visões dos governos nacionais e locais. Além disso, a distância dos órgãos decisórios do MERCOSUL, o Conselho Mercado Comum (CMC) e o Grupo Mercado Comum (GMC), aumentava o abismo entre governantes locais e nacionais, afastando as possíveis recomendações dos municípios de uma analise política decisória a ponto de desestimular qualquer ação institucional da REMI e de seus membros". Com isso, esta instância foi substituída, em 2004, pelo FCCR.
} 
58 InterAção

transitória do Regimento Interno do FCCR, é presidido pela Secretaria Executiva da Mercocidades ${ }^{7}$ (MERCOSUL;FCCR, 2014).

Desse modo, é por este órgão que a Rede pode estabelecer o diálogo com o MERCOSUL, enviando-lhe recomendações. Por um lado, isto legitima a Rede como ator no processo de integração mercosulino (DE MATOS; STEFFEN, 2012, p. 37). Por outro, o caráter ainda consultivo deste órgão junto à estrutura institucional do MERCOSUL não garante que as recomendações enviadas serão adotas pelos órgãos decisórios do bloco e, assim, transformadas em normativa deste, o que dificulta um maior impacto da atuação da rede para a tomada de decisões do bloco regional.

Mas, esta participação traz outras oportunidades para que a Rede tenha influência na integração regional junto às suas cidades sócias. Uma delas é a possibilidade de o FCCR, como órgão do MERCOSUL, apresentar projetos de desenvolvimento regional junto ao Fundo de Convergência Estrutural do MERCOSUL (FOCEM) $)^{8}$, os quais podem ser originados de propostas trazidas pela Rede no comando do COMUM. Para tanto, é preciso reforçar a influência política do referido órgão nas decisões tomadas pelo FCCR, a fim de que impulsione as propostas apresentadas pelas cidades.

Ainda, oportunidades de participação relevante para a Rede junto ao MERCOSUL se referem a laços estabelecidos com outros órgãos do bloco. Exemplo disso é o Convênio firmado entre a Rede e o Instituto Social do

\footnotetext{
${ }^{7}$ Segundo 0 art. 27, do Regimento Interno do FCCR, "até dezembro de 2008, a Coordenação do Comitê de Municípios estará a cargo do governo local que exerça a Secretaria Executiva da Rede de Mercocidades" (MERCOSUL; FCCR, 2014). Contudo, até a finalização deste artigo, em final de 2014, não havia se concretizado revisão ou reforma do referido Regimento para estabelecer, definitivamente, a representação dos governos municipais, mantendo-se a Secretaria Executiva da Rede, ainda temporariamente, no cargo.

80 Fundo para a Convergência Estrutural do MERCOSUL (FOCEM) foi criado pela Decisão CMC № 45/04. É um fundo destinado a financiar programas para promover a convergência estrutural; desenvolver a competitividade; promover a coesão social e apoiar o funcionamento da estrutura institucional e o fortalecimento do processo de integração. (MERCOSUL; FOCEM, 2014).
} 
59 | InterAção

MERCOSUL (ISM) ${ }^{9}$ (MERCOCIDADES; ISM, 2014e), que visa à cooperação em pesquisas, análise, promoção e difusão de processos e políticas de fortalecimento da integração, pela redução de assimetrias entre os Estados membros do bloco e pelo desenvolvimento humano integral, com articulação das políticas sociais. Também é exemplo disso a aproximação que vem se estabelecendo entre a Rede e a Unidade de Apoio à Participação Social do MERCOSUL (UPS), órgão do bloco que busca fortalecer os mecanismos de participação social em sua estrutura. A Rede e a UPS, atualmente, negociam a realização de convênio, a fim de que esta possa afiançar os laços daquela com os espaços do bloco (MERCOCIDADES, 2014d).

Frente a isso, a Rede têm encontrado espaços institucionais junto ao MERCOSUL para tentar, pela sua atuação, trazer reflexos das demandas municipais para a condução das atividades do bloco. Contudo, estes espaços, como não possuem competência decisória e normativa junto ao bloco, ainda muito atrelado às presidências e chancelarias dos Estados partes e associados, possuem impactos reduzidos para a tomada de decisões do MERCOSUL. É preciso, portanto, fortalecer politicamente tais espaços, para que mudanças mais concretas possam ser operadas, a fim de garantir um papel mais relevante aos governos locais no âmbito do bloco.

Ademais, para que a Rede possa influenciar no desenvolvimento da integração regional sul-americana, é preciso encontrar espaços também em outros foros regionais e internacionais ${ }^{10}$. Um foro importante para tanto é a

\footnotetext{
${ }^{9} 0$ Instituto Social do MERCOSUL (ISM) é um órgão técnico-político, estabelecido em 2007 (CMC/DEC № 03/07), como resultado da iniciativa da Reunião de Ministros e Autoridades de Desenvolvimento Social do Mercosul (RMADS). Efetua pesquisas sobre políticas sociais e implementação de linhas estratégicas para consolidar a dimensão social do bloco e realiza iniciativas que contribuam à redução das assimetrias sociais entre os Estados Partes e para promoção do desenvolvimento humano integral. (MERCOSUL; ISM, 2014).

${ }^{10}$ A partir das linhas de atuação trabalhadas nas Unidades Temáticas, a Rede mostra seu desempenho através de termos de cooperação formados com outras instituições e organizações, como por exemplo, a parceria com 0 Escritório para Redução de Riscos de Desastres das Nações Unidas (UNISDR), que objetiva preparar as cidades
} 
60 | InterAção

UNASUL, bloco regional que, recentemente, estabeleceu relações de complementaridade e articulação com o MERCOSUL. Diante disso, é preciso perquirir se há possibilidade de interação entre a UNASUL e a Rede Mercocidade, com vistas a ampliar sua atuação na região. É o que segue.

\section{A POSSIBILIDADE DE INTERAÇÃO DA REDE MERCOCIDADES COM A UNASUL}

No final da década de 1990 e início dos anos 2000, a agenda da integração regional sul-americana passa a abarcar novas questões, em decorrência do "novo ciclo político" (BÉRMUDEZ TORRES, 2011, p. 121), que promoveu a renovação política e ideológica dos governos nacionais sul-americanos. Nesse viés, houve o relançamento do MERCOSUL 11 , que, de um bloco voltado à integração apenas econômico-comercial, passa a abarcar agendas de cooperação em temas como democracia, direitos humanos, educação, cultura, entre outras. Na esteira deste movimento ${ }^{12}$, surge a União Sul-americana de Nações (UNASUL), em 2008, em Brasília (UNASUL, 2014a).

propícias a desastres naturais para seu enfrentamento, trabalhando com governos locais dos países do MERCOSUL. Outro exemplo de cooperação da Rede, é o convênio com o Fundo Andaluz de Municípios para a Solidariedade (FAMSI), que engloba as linhas de atuação de cooperação transfronteiriça, integração regional, desenvolvimento sustentável e participação cidadã. Outra linha de atuação observada na prática se refere à educação e ao desenvolvimento da ciência e tecnologia, verificada na relação da Rede com a Associação de Universidades do Grupo Montevideo (AUGM), que objetiva fomentar a troca de conhecimento entre universidades públicas e áreas urbanas (MERCOCIDADES, 2014).

11 Em 2000, os Estados membros do bloco reuniram-se em Buenos Aires e acordaram sobre uma série de medidas visando revigora-lo e redireciona-lo, com ênfase na consolidação da união aduaneira, com vistas ao avanço ao mercado comum, no desenvolvimento das relações externas do bloco na região e, principalmente, esforços de maior coordenação nos planos político e social (VAZ, 2000, p. 3-4).

120 evento que abriu caminho para a constituição da UNASUL foi a criação da Comunidade Sul-americana de Nações (CSN ou CASA), durante a Terceira Reunião de Presidentes da América do Sul, em 2004, no Peru. A CSN nasceu para unir dois blocos regionais, o MERCOSUL e a Comunidade Andina (CAN). Durante as reuniões da CSN, em 2005, em Brasília e Cochabamba, os líderes dos países membros estabeleceram um plano estratégico e linhas de ação para a concretização de uma agenda comum de oportunidades e desafios. Não obstante, na primeira Cúpula Energética Sulamericana, ocorrida em 2007, na Venezuela, a CSN mudou sua denominação para UNASUL. Em 2008, depois de 
61 InterAção

A UNASUL é composta por Argentina, Bolivia, Brasil, Chile, Colômbia, Equador, Guiana, Paraguai, Peru, Suriname, Uruguai e Venezuela (UNASUL, 2014a). Tem como objetivo construir, de modo participativo e consensuado, um espaço de integração e união nos âmbitos cultural, social, econômico e político, priorizando o diálogo político, as políticas sociais, a educação, a energia, a infraestrutura, o financiamento e o meio ambiente, entre outros. Visa, com isso, a eliminar a desigualdade socioeconômica, alcançar a inclusão social e a participação cidadã, fortalecer a democracia e reduzir as assimetrias entre os Estados (UNASUL, 2014a).

Sua estrutura institucional é formada pelos seguintes órgãos: a) Conselho de Chefes de Estado e de Governo; b) Conselho de Ministros das Relações Exteriores; c) Conselho de Delegados e d) Secretaria Geral (UNASUL, 2014a). Ainda, conta com doze (12) Conselhos Setoriais, de nível ministerial, os quais abordam diversas temáticas (UNASUL, 2014c), sobre os quais se tratará mais adiante. Também, possui outras instâncias, como a Secretaria UNASUL-Haiti, para cooperação sul-americana com este país, e o Instituto Sul-Americano de Governo em Saúde, que objetiva a formação de lideranças, gestão do conhecimento e apoio técnico aos sistemas de saúde dos Estados membros (UNASUL 2014c).

Frente a isso, é plausível entender que este fenômeno constitui esforço complementar ao MERCOSUL, podendo, ainda, contribuir, para o fortalecimento da unidade de toda a América Latina e o Caribe (TAUNAY FILHO, 2008, p.18). De fato, conforme Cervo e Bueno, "mesclam-se decisões mercosulinas com decisões sul-americanas, demonstrando a imbricação desejada

sucessivas aproximações iniciadas com a Primeira Reunião de Presidentes da América do Sul, no ano 2000, realizouse, em Brasília, a Reunião Extraordinária do Conselho de Chefes de Estado e de Governo, que aprovou o Tratado Constitutivo da UNASUL, designando Quito, no Equador, como sede permanente de sua Secretaria Geral, e Cochabamba, na Bolivia, a sede de seu Parlamento. (UNASUL, 2014b). 
62 InterAção

dos dois processos de integração" (2008, p. 513). E isto se tornou ainda mais concreto quando da edição da Decisão n. 24/2012 do CMC, na qual se estabelecem oficialmente relações de complementação e articulação deste bloco com a UNASUL (MERCOSUL, 2012).

Estas relações destinam-se a estabelecer vínculos entre políticas, acordos e compromissos entre os dois blocos, a fim de otimizar recursos, evitar a superposição de tarefas e potencializar os esforços promovidos para a integração sul-americana (MERCOSUL, 2012). No marco desta decisão é que a Guiana e o Suriname, membros da UNASUL, iniciaram seus processos de adesão ao MERCOSUL, como membros associados, os quais se encontram em andamento (MERCOSUL, 2014b).

Nesse sentido, estas relações de complementaridade e articulação entre os dois blocos permitem perquirir sobre a possibilidade de a Rede Mercocidades também interagir com a UNASUL. Todavia, este bloco, ao contrário do MERCOSUL, não possui em sua estrutura institucional um órgão específico para representação de interesses locais. Para que se possa investigar a possibilidade de atuação da Rede junto à UNASUL, é preciso, então, verificar se há compatibilidade de agendas entre estas entidades.

Da mesma forma que a Mercocidades possui Unidades Temáticas, a UNASUL dispõe dos antes mencionados Conselhos Setoriais, sendo estes referentes aos seguintes aspectos: Energia, Saúde, Defesa, Infraestrutura e Planejamento, Desenvolvimento Social, Problema Mundial das Drogas, Educação, Cultura, Ciência, Tecnologia e Inovação, Economia e Finanças. E, possui dois grupos de Trabalhos, sobre Integração Financeira e Solução de Controvérsias em Matéria de Investimentos. (UNASUL, 2014c) 
63 | InterAção

Frente a isso, o exame de estrutura da UNASUL, constituída como um foro para debate dos desafios sul-americanos, permite constatar que é possível a inserção de atores subnacionais, apesar de nela não haver um espaço institucional oficial para tanto. Percebe-se que, tanto na UNASUL quanto na Rede Mercocidades, há áreas temáticas e projetos de trabalho em comum, os quais são equiparados no quadro abaixo.

Quadro 1- Temas em comum.

\begin{tabular}{|c|c|}
\hline REDE MERCOCIDADES & UNASUL \\
\hline $\begin{array}{l}\text { Unidade Temática de Segurança } \\
\text { Cidadã. }\end{array}$ & $\begin{array}{l}\text { Conselho de Defesa Sul-americano. } \\
\text { Conselho Sul Americano sobre } \\
\text { Segurança Cidadã, Justiça e } \\
\text { Coordenação da Ação contra a } \\
\text { Criminalidade } \\
\text { Transnacional. }\end{array}$ \\
\hline $\begin{array}{ll}\text { Unidade Temática } & \text { de } \\
\text { Desenvolvimento Social. } & \\
\text { Comissão de Direitos Humanos. } & \\
\text { Unidade Temática de Juventudes. } & \\
\end{array}$ & $\begin{array}{l}\text { Conselho Sul Americano para o } \\
\text { Desenvolvimento Social. } \\
\text { Conselho Eleitoral da Unasul. } \\
\end{array}$ \\
\hline $\begin{array}{l}\text { Unidade Temática } \\
\text { Desenvolvimento Urbano. } \\
\text { Unidade Temática de Ambiente e } \\
\text { Desenvolvimento Sustentável. } \\
\text { Unidade Temática de Planejamento } \\
\text { Estratégico. }\end{array}$ & $\begin{array}{l}\text { Conselho de infraestrutura } \\
\text { planejamento. }\end{array}$ \\
\hline $\begin{array}{l}\text { Unidade Temática de } \\
\text { Desenvolvimento Econômico Local. } \\
\text { Comissão de Economia Social e } \\
\text { Solidária. } \\
\text { Comissão de Fomento de Negócios. }\end{array}$ & $\begin{array}{l}\text { Conselho Sul Americano de Economia } \\
\text { e Finanças. }\end{array}$ \\
\hline Unidade Temática de Educação. & $\begin{array}{lll}\text { Conselho Sul Americano de } \\
\text { Educação. }\end{array}$ \\
\hline $\begin{array}{l}\text { Unidade Temática de Cultura. } \\
\text { Grupo de Trabalho em Cultura do } \\
\text { Esporte, a Atividade Física e a } \\
\text { Recreação. }\end{array}$ & Conselho Sul Americano da Cultura. \\
\hline
\end{tabular}


$64 \mid$ InterAção

\begin{tabular}{|l|l|}
\hline Unidade Temática de Turismo. & \\
\hline $\begin{array}{l}\text { Unidade Temática de Ciência, } \\
\text { Tecnologia e Capacitação. }\end{array}$ & $\begin{array}{l}\text { Conselho Sul Americano de Ciência, } \\
\text { Tecnologia e Inovação. }\end{array}$ \\
\hline
\end{tabular}

FONTE: MERCOCIUDADES, 2014c; UNASUR, 2014c

Elaborado pela autora Larissa Roxanne Baum.

Porém, nem todas as Unidades Temáticas e Conselhos Setoriais coincidem nas questões que abordam. A Rede Mercocidades possui algumas áreas temáticas nas quais a UNASUL não trabalha exclusivamente junto a algum Conselho Setorial, por exemplo. O Quadro 2, abaixo, expõe estas diferenças. Porém, isso não significa que a Rede ou a Organização não trabalhe com esse tema de outra forma, mas apenas que não se intercalam e/ou não trabalham de forma explícita em uma Unidade ou Conselho.

Quadro 2 - Diferenças (Temas de UT's e Conselhos que não se intercalam).

\begin{tabular}{|c|c|}
\hline Rede Mercocidades & Unasul \\
\hline $\begin{array}{l}\text { Unidade Temática de Cooperação } \\
\text { Internacional. }\end{array}$ & Conselho Energético Sul Americano. \\
\hline $\begin{array}{l}\text { Unidade Temática de Gênero e } \\
\text { Município. }\end{array}$ & Conselho Sul Americano de Saúde. \\
\hline $\begin{array}{l}\text { Unidade Temática de Integração } \\
\text { Fronteiriça. }\end{array}$ & $\begin{array}{l}\text { Conselho Sul Americano sobre o } \\
\text { Problema Mundial das Drogas. }\end{array}$ \\
\hline $\begin{array}{l}\text { Unidade Temática de Autonomia, } \\
\text { Gestão e Participação. }\end{array}$ & \\
\hline
\end{tabular}

FONTE: MERCOCIUDADES, 2014c; UNASUR, 2014c

Elaborado pela autora Larissa Roxanne Baum.

Nesse viés, constata-se que existem mais semelhanças do que diferenças entre os temas abordados pela Rede e pela Organização, o que contribui para uma possível interação entre ambas Esta interação, num primeiro momento, a fim de promover a aproximação entre as entidades, poderia se dar por meio da realização de eventos, como reuniões, encontros, cúpulas, permitindo a discussão conjunta sobre tais temas. Num segundo momento, poder-se-ia, como a Rede já efetuou junto ao MERCOSUL, buscar o estabelecer convênios e acordos, para 
65 | InterAção

delinear estratégias comuns ou compartilhadas de ação. Desse modo, este pode ser o início do caminho que leve a uma participação institucionalizada da Rede junto a este bloco.

\section{CONSIDERAÇÕES FINAIS}

A intensificação na tendência hodierna de os atores subnacionais assumirem maior autonomia nas relações internacionais, para apresentar e concretizar seus interesses no ambiente global, serve de alerta para os organismos internacionais e as instituições do direito internacional. Como visto no decorrer do artigo, esses atores demandam espaço para sua inserção, e os processos de integração regional se mostram aptos a os acolherem.

A Rede Mercocidades, como um desses atores, aproximou-se do MERCOSUL, operando junto a este. E, apresenta potencialidade de atingir outros foros regionais e internacionais, como a UNASUL, com a qual o MERCOSUL possui relações de complementaridade e articulação. Então, estas questões foram o objeto de análise deste trabalho.

Nesse passo, examinou-se como se dá a relação entre a Rede e o MERCOSUL, encontrando-se neste espaço institucionalizado para participação daquela. Este espaço é o FCCR, em que a Rede preside o Comitê de Municípios. Contudo, como se trata de órgão meramente consultivo, isto dificulta os reflexos da atuação da Rede em termos de influência nas decisões tomadas pelo bloco. Apesar disso, a Rede pode se utilizar da participação no referido Comitê, a fim de direcionar decisões do FCCR com relação ao encaminhamento de projetos de desenvolvimento regional ao FOCEM, fundo do MERCOSUL para financiamento deste tipo de projetos. 
66 | InterAção

Além disso, a Rede tem envidado esforços no sentido de garantir articulação com outros órgãos do MERCOSUL, que trabalhem com temas comuns aos seus, como é o caso do ISM, com o qual a Rede possui convênio de cooperação, e a UPS, com a qual a Rede tem efetuado aproximação, com vistas a futuro convênio. Assim, a Rede têm encontrado espaços institucionais junto ao MERCOSUL para tentar, pela sua atuação, incluir demandas municipais na condução das atividades do bloco, ainda que tais espaços precisem de reforço político para ter um maior e efetivo impacto para tanto.

Por outro lado, como a Rede apresenta interesse em não restringir sua atuação ao MERCOSUL, buscando ampliá-la a outras instituições, perquiriu-se sobre a possibilidade de sua interação com a UNASUL, a qual tem relações complementares com o MERCOSUL. Nesse sentido, verificou-se que entre Mercocidades e UNASUL há simetria de temas abordados por seus órgãos, bem como que estas entidades são dirigidas por e direcionadas a atores e público comuns. Assim, pode-se considerar que há espaço para interação entre ambas. Isto pode, então, se dar mediante a aproximação inicial, via realização de eventos para discussões conjuntas, evoluindo, posteriormente, ao estabelecimento de convênios e acordos, para, um dia, talvez, institucionalizar no bloco sulamericano um espaço de participação aos governos subnacionais representados pela Rede.

\section{REFERÊNCIAS}

ANDRADE E BARROS, Marinana. Atuação internacional dos governos subnacionais. Belo Horizonte: Del Rey, 2010. 
$67 \mid$ InterAção

BERMUDEZ TORRES, César Augusto. MERCOSUR Y UNASUR: Una mirada a la integración regional a comienzos del siglo XXI. Analisis

Político, Bogotá, v.24, n. 72, p. 115-131, mai/ago. 2011.

CASTELO BRANCO, Álvaro Chagas. A paradiplomacia como forma de inserção internacional de unidades subnacionais. Prismas: Dir., Pol.Pub. e Mundial., Brasília, v.4, n, 1, p. 48-67, jan/jul. 2007.

CERVO, Amado Luiz; BUENO, Clodoaldo. História da Política Exterior do Brasil. Brasília: UNB, 2008.

DE MATOS, Giovanna Arjonilla; STEFFEN, Nathalie Padovani. A rede Mercocidades e o Mercosul: atuação em rede através do FCCR. Conjuntura Internacional, Belo Horizonte, v.9, n. 5, p. 31 - 39, 2o sem. 2012.

DUCHACEK, Ivo D. Perforated sovereignties: toward a typology of new actors in international relations. In: MICHELMANN, H. J; SOLDATOS, P. Federalism and international relations: the role of subnational units. Nova York: Oxford University Press, 1990, p. 16-27.

FRONZAGLIA, M. L. Unidades Subnacionais: um estudo de caso sobre a cidade de São Paulo - de 2001 a 2004. Dissertação de Mestrado. Instituto de Filosofia e Ciências Humanas. Universidade de Campinas. Campinas, 2005.

HAFTECK, Pierre. An Introduction to Decentralized Cooperation: Definitions, Origens, and Conceptual Mapping. Public Administration and Development, n. 4, p. 333-345, Out./2003.

KLEIMAN, Alberto. Processo de Institucionalização de Mercocidades. Da REMI ao FCCR. In: MERCOCIDADES. 15 Años de Mercociudades. Rosario: Aquatint, 2010, p. 61-64.

MERCOCIDADES. Estatuto y Reglamento de Mercociudades. Disponível em: http:/ / www.mercociudades.org/node/2273. Acesso em: 22 ago. 2014a.

Autoridades. Consejo. Disponível em:

http:// www.mercociudades.org/node/2275\#consejo. Acesso em: 22 ago. $2014 b$.

Unidades Temáticas. Disponível em:

http://www.mercociudades.org/node/2286. Acesso em: 22 ago. 2014c.

Avanços e Proposta de Trabalho da Unidade de Participação Social do MERCOSUL. Disponível em: http:/ / www.mercociudades.org/ptbr/node/4666. Acesso em: 22 ago. 2014d. 
68 InterAção

; ISM. Convênio Marco de Cooperação entre o Instituto Social do

MERCOSUL e a Rede Mercocidades. Disponível em:

http:// mercociudades.org/sites/portal.mercociudades.net/files/Convenio $\% 20$

de\%20Cooperaci\%C3\%B3n_Mercociudades_ISM_firmado \%205\%20nov_2012.p

df. Acesso em: 22 ago. 2014e.

MERCOSUL. CMC/Decisão n. 41/2004. Disponível em:

http://www.mercosur.int/innovaportal/v/580/1/secretaria/decisiones_2004. Acesso em: 22 ago. 2014.

Em poucas palavras. Disponível em:

http:/ / www.mercosur.int/t_generic.jsp?contentid=3862\&site=1\&channel=secr etaria\&seccion=2. Acesso em: 22 ago. $2014 \mathrm{~b}$.

CMC/Decisão n. 24/2012. Disponível em:

http://www.mercosur.int/innovaportal/v/580/1/secretaria/decisiones_2012. Acesso em: 05 out. 2012.

; FCCR. Regimento Interno do FCCR. Disponível em:

https://www.mrecic.gov.ar/userfiles/regimento_fccr_port.pdf. Acesso em: 22 ago. 2014.

; FOCEM. O que é o FOCEM? Disponível em:

http:// www.mercosur.int/focem/index.php?id=que-es-el-focem. Acesso em: 22 ago. 2014.

; ISM. Institucional. Disponível em: http:/ / ismercosur.org/ptbr/institucional/. Acesso em: 22 ago. 2014.

PRAZERES, Tatiana Lacerda. Por uma atuação constitucionalmente viável das unidades federadas brasileira. In: VIGEVANI, Tullo (Org.). A dimensão subnacional e as reações internacionais. São Paulo: Unesp, 2004, p. 283-312.

RODRIGUES, Gilberto Marcos Antonio. Política Externa Federativa. Análise de Ações Internacionais de Estados e Municípios Brasileiros. Tese de doutorado. PUC-SP. São Paulo, 2004.

TAUNAY FILHO, Jorge. Comunidade Sul-americana de Nações - CASA. In: CONFERÊNCIA NACIONAL DE POLÍTICA EXTERNA E POLÍTICA INTERNACIONAL. Seminário América do Sul. Brasília: FUNAG, 2008, p. 11 32.

UNASUL. Tratado Constitutivo da UNASUL. Disponível em: http://www.itamaraty.gov.br/temas/america-do-sul-e-integracaoregional/unasul/tratado-constitutivo-da-unasul. Acesso em: 22 ago. 2014a. 
69 InterAção

História. Disponível em:

http:// www.unasursg.org/inicio/organizacion/historia. Acesso em: 22 ago. $2014 b$.

Órgãos. Disponível em:

http://www.unasursg.org/inicio/organizacion/organos. Acesso em: 22 ago. 2014c.

VAZ, Alcides Costa. O Relançamento do MERCOSUL. Boletim Meridiano 47, Brasília, n. 1, p. 3-4, jul. 2000. 